\title{
Exploring a 1-Minute Paced Deep-Breathing Measurement of Heart Rate Variability as Part of a Workers' Health Assessment
}

\author{
Marianne Six Dijkstra ${ }^{1,5}$ (1) $\cdot$ Remko Soer $^{1,2} \cdot$ André Bieleman $^{1} \cdot$ Rollin McCraty $^{3} \cdot$ Frits Oosterveld ${ }^{1} \cdot$ Douglas Gross $^{4}$. \\ Michiel Reneman ${ }^{5}$
}

Published online: 1 December 2018

(C) The Author(s) 2018

\begin{abstract}
Low heart rate variability (HRV) is related to health problems that are known reasons for sick-leave or early retirement. A 1-minute-protocol could allow large scale HRV measurement for screening of health problems and, potentially, sustained employability. Our objectives were to explore the association of HRV with measures of health. Cross-sectional design with 877 Dutch employees assessed during a Workers' Health Assessment. Personal and job characteristics, workability, psychological and mental problems, and lifestyle were measured with questionnaires. Biometry was measured (BMI, waist circumference, blood pressure, glucose, cholesterol). HRV was assessed with a 1-minute paced deep-breathing protocol and expressed as mean heart rate range (MHRR). A low MHRR indicates a higher health risk. Groups were classified age adjusted for HRV and compared. Spearman correlations between raw MHRR and the other measures were calculated. Significant univariable correlations $(p<0.05)$ were entered in a linear regression model to explore the multivariable association with MHRR. Age, years of employment, BMI and waist circumference differed significantly between HRV groups. Significant correlations were found between MHRR and age, workability, BMI, waist circumference, cholesterol, systolic and diastolic blood-pressure and reported physical activity and alcohol consumption. In the multivariable analyses $21.1 \%$ of variance was explained: a low HRV correlates with aging, higher BMI and higher levels of reported physically activity. HRV was significantly associated with age, measures of obesity (BMI, waist circumference), and with reported physical activity, which provides a first glance of the utility of a 1-minute paced deep-breathing HRV protocol as part of a comprehensive preventive Workers' Health Assessment.
\end{abstract}

Keywords Employment $\cdot$ Workers $\cdot$ Screening $\cdot$ Heart rate variability $\cdot$ Diagnostic techniques and procedures

Marianne Six Dijkstra

w.m.c.sixdijkstra@saxion.nl

1 Saxion University of Applied Sciences/AGZ, M.H. Tromplaan 28, 7500 KB Enschede, The Netherlands

2 Groningen Spine Center, University Medical Center Groningen, University of Groningen, Groningen, The Netherlands

3 Heartmath LCC, Boulder Creek, CA, USA

4 Department of Physiotherapy, University of Alberta, Edmonton, Canada

5 Department of Rehabilitation Medicine, University Medical Center Groningen, University of Groningen, Groningen, The Netherlands

\section{Introduction}

With an aging workforce (Douwes et al. 2014; Duin and Stoeldraijer 2013; Sas and Suarez 2014), the need increases to preserve health and wellbeing as employees work until retirement age. Ageing leads to an increased risk of developing chronic diseases (Sas and Suarez 2014). Chronic diseases in ageing workers are associated with decreased workability (Leijten et al. 2014) and health issues are the most common reason for leaving the workforce before the statutory retirement age (Perosh 2014). Workers with long sickness absence are more likely to exit the labor force through disability benefits and unemployment (Reeuwijk et al. 2015).

In the Netherlands, the main reasons for calling in sick longer than 3-4 weeks are psychological (33\%) and musculoskeletal (28.9\%) problems. In the group of 'other diagnoses' $(38.1 \%)$, the main reasons for long term sick-leave 
are coronary heart disease (4.9\%), intestinal (4.8\%) and neurological (4.7\%) problems (Volksgezondheidenzorg. info 2017). Between 2007 and 2013, the number of absent days due to concentration problems and fatigue increased. When duration of sick-leave is accounted for, musculoskeletal problems, psychological problems, including burnout and being overworked account for $40 \%$ of the total sick-leave volume. Early identification of these potentially modifiable health problems and prevention initiatives could decrease sick-leave and improve sustained employability (Leijten et al. 2014).

Workers' Health Assessments (WHA) are used to identify specific work-related risks in order to prevent injuries or disease to promote sustained employability (WHO 2002; van Holland et al. 2015; Weel et al. 2007). A periodic medical examination can be part of a WHA (Aldana et al. 2005). Health status and work-related problems are often assessed with biometrical measurements and questionnaires. Biometrical measurements can be used to assess risk for metabolic syndrome, diabetes and coronary heart disease. Self-report measures often include the Work Ability Index (WAI), which aims specifically at determining workability (Ilmarinen 2009) and includes questions on neurological, intestinal and coronary heart diseases. A large number of other questionnaires may be used to assess the physical and mental health status and associated risks, as well as perceived work strain. All parameters together provide information about the health and sustained employability status of the employee. However, the construct of sustained employability is difficult to measure and more objective measures may increase the chances for finding workers with healthrelated threats to sustained employability.

One biometrical concept that may be related to sustained employability is heart rate variability (HRV). HRV is associated with physical and mental health issues (Beauchaine and Thayer 2015; Geisler et al. 2013; McCraty et al. 1998; Wulsin et al. 2015) and, in turn, potentially to sustained employability. HRV is a measure of the consecutive differences in time between heartbeats. The oscillation in the beat-to-beat interval of heart rate is the result of hormonal, neural and mechanical interactions of local and central systems (heart rate variability: standards of measurement, physiological interpretation and clinical use. Task Force of the European Society of Cardiology and the North American Society of Pacing and Electrophysiology 1996). HRV is a marker for functioning of the autonomic nervous system (Shaffer et al. 2014). The time variations between consecutive heartbeats in a healthy heart are large and reflect the ability of the brain, autonomic nervous system and heart to adapt to changing circumstances. HRV declines with age (Umetani et al. 1998), but lower HRV values are also an independent predictor of decreased health (Dekker et al. 2000). Low HRV is indicated as a predictor for metabolic syndrome and cardiovascular diseases (Dekker et al. 2000; Liao et al. 1998; Licht et al. 2013; Thayer and Lane 2007; Tsuji et al. 1996; Wulsin et al. 2016). Low HRV has been observed in patients with diabetes, hypertensive cardiac hypertrophy and atherosclerosis. Low HRV is also associated with lower self-regulation and resilience (Geisler et al. 2013), with lower mental and social flexibility (Geisler et al. 2013; Williams et al. 2015), was found to be a marker for fatigue (Volker et al. 2016), and is more present in people with clinical burnout compared to healthy controls (Lennartsson et al. 2016). Summarized, a low HRV for one's age is related to several health issues that may compromise a worker's sustained employability. There is, however, insufficient knowledge about the additional value of measuring HRV in a working population with the focus on sustained employability.

For HRV, 24-h measurements are considered the gold standard but are expensive and time consuming. However, new technologies now enable HRV measurement in the occupational setting as a potential health screen. With photo plethysmography (PPT) technology, rapid and non-invasive measurements became available. Promising results have been reported for a drastically shortened 1-minute paced deep-breathing protocol (Russoniello et al. 2013). The next step to validate HRV as a potential screening instrument for future SE will be to explore associations of HRV with health related issues. Therefore, the objectives of this study are to: (1) compare the WHA outcomes of workers with a very low, low and normal HRV; and (2) examine associations between a 1-minute HRV measurement and health related outcomes derived from a WHA.

\section{Methods}

\section{Study Design and Setting}

A cross-sectional design was carried out. In the Netherlands, employers of moderate or large companies are required to offer their workers a voluntary health assessment, performed by an independent occupational healthcare supplier (OHS). Data from WHAs that were part of a regular health screening service were collected between November 2015 and June 2016 and explored in relation to HRV. Three OHS's performed the measurements examined in the current study. The Ethics Board at the University Medical Center Groningen in The Netherlands decided that formal approval of the study was not necessary because all workers were subjected to care as usual only.

\section{Participants}

Workers from divisions of 14 companies in the Netherlands were included. All workers were invited to participate. The 
company was responsible for the invitation process. Data of workers between 18 and 65 years were used. Pregnant women and workers with severe health problems who were currently absent from work and workers with pacemakers were excluded from this study.

\section{Data Collection}

The WHA data were collected using two procedures. The first was an online questionnaire completed at home (30-45 $\mathrm{min}$ ) prior to assessment. The second procedure was a physical assessment that included biometric measurements collected by a physician assistant or occupational physical therapist (OPT) at the company (25 min). Immediately after the biometric measurements, there was a counseling session with an OPT ( $25 \mathrm{~min})$. The time between answering the questionnaire and the biometry measurements varied between 2 weeks and $1 \mathrm{~h}$. For HRV, raw data were collected during the test in the emWave ${ }^{\circledR}$ Pro Plus software (Heartmath Institute, Boulder Creek). The participants were asked not to eat or drink for 45 min prior to the appointment (which was 60 min prior to the HRV measurements), and to avoid heavy physical work during the last hour.

\section{Measurements}

\section{Questionnaires}

Personal (age, sex, level of education) and work characteristics [working hours per week, number of years employed, workload [categories of the Dictionary of Occupational Titles (DOT)] were registered. In the DOT, occupations are classified into five categories of physical workload, based on intensity and duration of lifting or carrying needed for the job: sedentary, light, medium, heavy/very heavy. Because very heavy work hardly exists in the Netherlands, the last two categories were combined (Soer et al. 2009).

The following questionnaires were administered for the study:

1. Work Ability was measured with the short version of the Work Ability Index (WAI). It consists of seven items (Tuomi et al. 1998). The WAI has been shown to be valid for determination of sustained employability (Alavinia et al. 2008; de Zwart et al. 2002; Radkiewitz and Widerszal-Bazyl 2005) and is internally consistent [Cronbach's alpha 0.72-0.80 (Tuomi et al. 2004)]. The scale ranges between 7 and 49, with higher scores indicating better workability. WAI can be used to identify workers at high risk for prolonged sickness absence (Reeuwijk et al. 2015).
2. Work engagement was measured with the Utrecht Work Engagement Scale-9 (UWES-9) (Schaufeli et al. 2006; Schaufeli and Bakker 2003). The UWES-9 consists of nine questions and assesses 'work engagement'. It consists of three subscales, measuring dedication (three questions), vigor (three questions), and absorption (three questions), with a $0-6$ point scale per question. The total scale ranges between 0 and 54, with a higher score indicating more engagement. Psychometric properties of the questionnaire are good (Schaufeli et al. 2006; Schaufeli and Bakker 2003).

3. Psychological problems were measured with the General Health Questionnaire-12 (GHQ-12) (Koeter and Ormel 1991; Sluiter and Hulshof 2013), consisting of 12 questions with 4 possible answers; 2 are valued positive $($ score $=0)$ and 2 negative $($ score $=1)$. The scale ranges between 0 and 12, with a lower score indicating less functional psychological problems.

4. Perceived Workload was measured with subscales of the Questionnaire on the Experience and Evaluation of work (QEEW, in Dutch: VBBA) (Veldhoven et al. 2002): need for recovery (NfR, 11 items)—Workpace (Wp, 11 items)—perceived mental strain (MS, 9 items). Subscale scores range between 0 and 100, and a lower score indicates more favorable situations. Reliability is satisfactory (Veldhoven et al. 2002).

5. A lifestyle questionnaire asking about physical activity, smoking, alcohol, nutrition and recreation. The questionnaire is descriptive in nature, based on guidelines (RIVM 2016), and has not been validated as an outcome measure. The results are scored with an ordinal scale $1-3$, with a lower score indicating healthier behavior.

Detailed information about the full protocol and interpretation of results is based on guidelines as presented in Appendix 1.

\section{Heart Rate Variability}

HRV was measured with the ear lobe pulse sensor of the emWave ${ }^{\circledR}$ Pro Plus. The emWave ${ }^{\circledR}$ Pro Plus uses photo pletysmography (PPG) technology, which is based on the ability of hemoglobin to absorb light and can measure the blood pulse wave through the skin. PPG technology is a reliable and valid method of capturing and quantifying HRV from a deep breathing test (Russoniello et al. 2013). The HRV measurement was recorded individually in a quiet room, in a slightly reclined $\left(\sim 10^{\circ}\right)$ seated position. The sensor was placed on the earlobe and the participant was introduced to the emWave ${ }^{\circledR}$ Pro Plus software. Participants were instructed to remain seated and relaxed and to refrain from 
making any significant or rapid body movements. Participants were instructed to breathe according to the 1-minute, 6-breath protocol that was paced at a rhythm of 6 breaths per minute $(0.1 \mathrm{~Hz})$ while breathing as deeply as they comfortably could. This breathing method was designed to provide a physiological challenge to assess the maximum HRV range (amplitude) their system was capable of producing at that time (Shields 2009). A visual breath-pacer is used to facilitate the regularity of the breathing. The entire minute should be artefact-free. Compliance was closely monitored to ensure sufficient deep breathing and synchronization with the breath pacer. If quality was doubted, a second test was performed.

HRV is usually expressed by either time- or frequencydomain parameters (heart rate variability: standards of measurement, physiological interpretation and clinical use. Task Force of the European Society of Cardiology and the North American Society of Pacing and Electrophysiology 1996). For exploring the added value of HRV for a WHA, the mean heart rate range (MHRR) was used as outcome. The MHRR is a time domain variable indicating the magnitude of the amplitudes in acceleration and deceleration of the heart. The range of the interbeat intervals is measured and expressed in the average change in beats per minute (BPM). For each breathing cycle, the maximum in BPM is calculated and averaged over the 6 breaths to obtain the MHHR. MHRR has been suggested as a good indicator of autonomic nervous system health and biological age (Russoniello et al. 2013; Shields 2009) with the practical advantage that it can be explained easily to participants. Pearson correlation between MHRR and another regularly used measure, Root Mean Square of Successive Differences (RMSSD), was calculated to confirm the correlation between MHRR and RMSSD in this study compared to other studies.

\section{Biometric Measures}

Besides HRV, other biometric measures were: weight $(\mathrm{kg})$, body length $(\mathrm{m})$, waist circumference $(\mathrm{cm})$, systolic and diastolic blood pressure $(\mathrm{mmHg})$, glucose $(\mathrm{mmol} / \mathrm{l})$, and total cholesterol (mmol/l). BMI was also calculated (weight/ length ${ }^{2}$ ) (see Appendix 1 for full protocol and cut off values).

\section{Data Handling}

The EmWave Pro Plus ${ }^{\circledR}$ software calculated MHRR. All data from the questionnaires, biometry, and HRV were entered and processed in a software program from the OHS. All WHA data were compiled into an Excel file and de-identified by the OHS. The data were then sent to the researchers. Only data with a complete set for WHA and
HRV were used for statistical analyses. For descriptives, the data were divided into subgroups because literature indicates low HRV is related to health problems (Dekker et al. 2000; Geisler et al. 2013; Lennartsson et al. 2016; Liao et al. 1998; Licht et al. 2013; Shaffer et al. 2014; Thayer and Lane 2007; Tsuji et al. 1996; Volker et al. 2016; Williams et al. 2015; Wulsin et al. 2016). In absence of validated meaningful cutoff values, statistical criteria were used to determine cut-off values. Cut-off values are provided on the left side of the normal distribution of MHRR of a healthy reference group (proprietary, Emwave Pro Plus ${ }^{\circledR}$ software): very low HRV when MHRR $>2$ SD below mean, low HRV when MHRR is 1-2 SD below mean, normal-high HRV when the deviation is higher than $1 \mathrm{SD}$ below mean. Categorization of HRV was age corrected, because most variance of HRV is explained by age and we are interested in the contribution of other measures.

\section{Statistical Analyses}

First, to obtain insight into which levels of the WHA measures were observed in the workers with very low, low or normal-high HRV, descriptive results are presented for each group. Age was normally distributed and described with mean and standard deviation. The other personal and work characteristics and WHA data are provided with medians and minimum-maximum for ordinal and for skewed continuous data, frequencies and percentages for nominal data and the lifestyle-questionnaires data (because they have only three categories). Secondly, differences between groups were tested. An Anova was used for age. The other continuous variables were not normally distributed and therefore the non-parametric Kruskall-Wallis $H$ test was used. Then all single associations between raw MHRR and raw WHA measures were calculated with a Spearman correlation. The 95\% confidence interval (CI) around $r$ was calculated with a bootstrap accelerated procedure $(1000 \times)$. If the $95 \%$ CI did not cross zero, the association between MHRR and the WHA measure was considered significant. Finally a multivariable analysis was performed to explore the shared variance of combined measures (independent variables) to MHRR (dependent variable). The WHA measures with a significant single correlation with MHRR were included as independent measures for backward regression analyses. Continuous skewed data were $10 \log$ transformed to meet the assumptions for linear statistics and dummy variables were made for categorical data. A best fit was found with the independent measures that contributed significantly to the model $(p<0.05)$. Adjusted $\mathrm{R}^{2}$ was calculated for cross-validation of the model. All results were statistically analyzed with IBM SPSS Statistics 24.0 software. 


\section{Results}

\section{Participants}

Participation rate was $70-100 \%$ in the 14 included companies. 1420 Workers participated in the WHA; 155 were excluded from the study because they did not meet the inclusion criteria and 388 had incomplete WHA data, resulting in 877 participants included in the study. The majority of participants were male $(77 \%)$, mean age was 43.4 years $(S D=10.2$, range $=19-65)$. Most participants (44.0\%) performed work with moderate physical demands (DOT3) and had a high education level (49.3\%). Age $(F(2,874)=12.39, p=0.00)$ and years of employment $(H(2)=8.87, p=0.01)$ differed significantly between HRV groups; the post hoc Bonferroni and Mann-Whitney $U$ test revealed that the group with normal-high MHRR was significantly younger than the other two groups and employed shorter than the low MHRR group. Characteristics of participants and work are presented in Table 1, divided by HRV (MHRR) category.

\section{WHA Results}

The WHA measures are presented in Table 2, divided by HRV category.

\section{Mean Heart Rate Range}

In the studied population, when controlled for age $4.0 \%$ of the workers had a very low HRV, 5.5\% a low HRV, and 90.5\% had a normal-high HRV (Table 2).

\section{Questionnaires}

Median workability was good $(>41)$ in all groups. All groups reported being engaged, had few problems regarding need for recovery, psychological problems, or work
Table 1 Participants and work characteristics, divided by heart rate variability (MHRR) outcome

\begin{tabular}{|c|c|c|c|c|}
\hline & $\begin{array}{l}\text { Normal to } \\
\text { high MHRR } \\
n=794\end{array}$ & $\begin{array}{l}\text { Low MHRR } \\
\mathrm{n}=48\end{array}$ & $\begin{array}{l}\text { Very low MHRR } \\
\mathrm{n}=35\end{array}$ & $\begin{array}{l}\text { Total group } \\
\mathrm{n}=877\end{array}$ \\
\hline Age in years, mean (SD)* & $43(10)$ & $47(8)$ & $50(10)$ & $43(10)$ \\
\hline \multicolumn{5}{|l|}{ Gender, n (\%) } \\
\hline Male & $608(76.6)$ & $40(83.3)$ & $27(77.1)$ & $675(77.0)$ \\
\hline Female & $186(23.4)$ & $8(16.7)$ & $8(22.9)$ & $202(23.0)$ \\
\hline \multicolumn{5}{|l|}{ Education level, n (\%) } \\
\hline Very low & $24(3.0)$ & $1(2.1)$ & $1(2.9)$ & $26(0.3)$ \\
\hline Low & $91(11.5)$ & $9(18.8)$ & $7(20)$ & $107(12.2)$ \\
\hline Intermediate & $278(35.1)$ & 18 (37.6) & $15(42.9)$ & $311(35.4)$ \\
\hline High & $400(50.4)$ & $20(41.6)$ & $12(34.3)$ & $432(49.3)$ \\
\hline \multicolumn{5}{|l|}{ DOT category, n (\%) } \\
\hline DOT1 & $92(31.5)$ & $6(35.3)$ & $7(43.8)$ & $105(32.0)$ \\
\hline DOT2 & $65(22.3)$ & $7(41.2)$ & $3(18.8)$ & $75(23.1)$ \\
\hline DOT3 & $133(45.5)$ & $4(23.5)$ & $6(37.5)$ & $143(44.0)$ \\
\hline DOT4/5 & $2(0.7)$ & $0(0)$ & $0(0)$ & $2(0.0)$ \\
\hline \multicolumn{5}{|l|}{ Irregular shifts, n (\%) } \\
\hline Yes & $604(76.2)$ & $37(77.1)$ & $25(71.4)$ & $666(75.9)$ \\
\hline No & $189(23.8)$ & $11(22.9)$ & $10(28.6)$ & $210(23.9)$ \\
\hline \multicolumn{5}{|l|}{ Contract, n (\%) } \\
\hline Fixed & $633(90.3)$ & $39(92.9)$ & $27(96.4)$ & $699(79.7)$ \\
\hline Temporary & $68(9.7)$ & $3(7.1)$ & $1(3.6)$ & $72(8.2)$ \\
\hline Working hours/ week, median (min-max) & $40(4-48)$ & $40(20-48)$ & $38(1-56)$ & $40(1-56)$ \\
\hline Years employed, median $(\min -\max )^{*}$ & $5(0-48)$ & $6(1-39)$ & $8(1-46)$ & $5(0-48)$ \\
\hline
\end{tabular}

Level of education: very low $=$ no or elementary education; low =lower vocational education; intermediate $=$ intermediate vocational education and secondary higher level education; high $=$ bachelor or higher education; DOT $=$ dictionary of occupational titles. Three descriptives were not applied by everyone: DOT category, $n=325$; irregular shifts, $n=876$; contract, $n=871$

*Groups differ significantly with $\mathrm{p} \leq 0.05$ 
Table 2 Results of the Workers Health Assessment (WHA) measures, divided by heart rate variability (MHRR) outcome

\begin{tabular}{|c|c|c|c|c|}
\hline & $\begin{array}{l}\text { Normal-high MHRR } \\
\mathrm{n}=794 \\
\text { Median (min-max) }\end{array}$ & $\begin{array}{l}\text { Low MHRR } \\
\mathrm{n}=48 \\
\text { Median (min-max) }\end{array}$ & $\begin{array}{l}\text { Very low MHRR } \\
\mathrm{n}=35 \\
\text { Median (min-max) }\end{array}$ & $\begin{array}{l}\text { Total group } \\
\mathrm{n}=877 \\
\text { Median (min-max) }\end{array}$ \\
\hline MHRR (beats/min)* & $21.0(7.7-66.6)$ & $8.0(6-11)$ & $5.3(2-9)$ & $19.8(2-66.6)$ \\
\hline BP Diastolic (mmHg) & $80.0(54-120)$ & $80.0(65-107)$ & $81.0(65-103)$ & $80.0(54-120)$ \\
\hline BP Systolic (mmHg) & $132.0(96-205)$ & $135.0(104-180)$ & $136.0(110-185)$ & $132.0(96-205)$ \\
\hline Cholesterol (mmol/l) & $5.2(2.6-9.3)$ & $5.3(3.1-7.7)$ & $5.3(3.6-7.8)$ & $5.1(2.6-9.3)$ \\
\hline Glucose (mmol/l) & $4.8(1.2-16.8)$ & $4.7(2.7-12.7)$ & $4.7(2.6-7.2)$ & $4.8(1.2-16.8)$ \\
\hline $\mathrm{BMI}\left(\mathrm{kg} / \mathrm{m}^{2}\right) *$ & $25.4(17.5-42.6)$ & $26.6(19.8-37.9)$ & $26.3(18.4-41.3)$ & $25.5(17.5-42.6)$ \\
\hline Waist circumf. $(\mathrm{cm})^{*}$ & $92.0(59-140)$ & $96(77-131)$ & $95(71-127)$ & $93(59-140)$ \\
\hline WAI & $43.0(25-49)$ & $41.5(31-49)$ & $44.0(19-49)$ & $43.0(19-49)$ \\
\hline UWES-9 & $39.0(17-45)$ & $40.5(14-45)$ & $37.0(5-45)$ & $38.7(5-54)$ \\
\hline GHQ-12 & $0.0(0-7)$ & $0.5(0-10)$ & $1.0(0-12)$ & $0.0(0-12)$ \\
\hline QEEW-NfR & $18.2(0-64)$ & $9.1(0-91)$ & $18.2(0-91)$ & $18.2(0-91)$ \\
\hline QEEW-Wp & $33.3(18-67)$ & $30.3(9-58)$ & $36.4(0-100)$ & $33.3(0-100)$ \\
\hline \multirow[t]{2}{*}{ QEEW-MS } & $77.8(44-89)$ & $77.8(33-89)$ & $77.8(0-100)$ & $77.8(0-100)$ \\
\hline & $\begin{array}{l}\text { Normal-high MHRR } \\
\mathrm{n}=794 \\
\mathrm{n} \text { (percentage) }\end{array}$ & $\begin{array}{l}\text { Low MHRR } \\
\mathrm{n}=48 \\
\mathrm{n} \text { (percentage) }\end{array}$ & $\begin{array}{l}\text { Very low MHRR } \\
\mathrm{n}=35 \\
\mathrm{n} \text { (percentage) }\end{array}$ & $\begin{array}{l}\text { Total group } \\
\mathrm{n}=877 \\
\mathrm{n} \text { (percentage) }\end{array}$ \\
\hline \multicolumn{5}{|l|}{ Physical activity $^{\mathrm{a}}$} \\
\hline Normal risk & $307(38.7)$ & $20(41.7)$ & 17 (48.6) & $344(39.2)$ \\
\hline Intermediate risk & $63(7.9)$ & $3(6.3)$ & $2(5.7)$ & $68(7.8)$ \\
\hline High risk & $424(53.4)$ & $25(52.1)$ & $16(45.7)$ & $465(53.0)$ \\
\hline \multicolumn{5}{|l|}{ Smoking ${ }^{\mathrm{a}}$} \\
\hline Normal risk & $647(81.5)$ & $41(85.4)$ & $28(80)$ & $716(81.6)$ \\
\hline Intermediate risk & $16(2)$ & $1(2.1)$ & $1(2.9)$ & $18(2.1)$ \\
\hline High risk & $131(16.5)$ & $6(12.5)$ & $6(17.1)$ & $143(16.3)$ \\
\hline \multicolumn{5}{|l|}{ Alcohol $^{\mathrm{a}}$} \\
\hline Normal risk & $697(87.8)$ & $39(81.3)$ & $30(85.7)$ & $766(87.3)$ \\
\hline Intermediate risk & $81(10.2)$ & $7(14.6)$ & $4(11.4)$ & $92(10.5)$ \\
\hline High risk & $16(2.0)$ & $2(4.2)$ & $1(2.9)$ & $19(2.2)$ \\
\hline \multicolumn{5}{|l|}{ Nutrition $^{\mathrm{a}}$} \\
\hline Normal risk & $436(54.9)$ & $24(50)$ & $21(60)$ & $481(54.8)$ \\
\hline Intermediate risk & $86(10.8)$ & $4(8.3)$ & $11(31.4)$ & $101(11.5)$ \\
\hline High risk & $272(34.3)$ & $20(41.7)$ & $3(8.6)$ & $295(33.6)$ \\
\hline \multicolumn{5}{|l|}{ Recreation $^{\mathrm{a}}$} \\
\hline Normal risk & $388(48.9)$ & $30(62.5)$ & 17 (48.6) & 435 (49.6) \\
\hline Intermediate risk & $274(34.5)$ & $14(29.2)$ & $13(37.1)$ & $301(34.3)$ \\
\hline High risk & $132(16.6)$ & $4(8.3)$ & $5(14.3)$ & $141(16.1)$ \\
\hline
\end{tabular}

MHRR mean heart rate range, WAI Work Ability Index-short version, scale 7-49, UWES-9 Utrecht Work Engagement Scale-9 questions (scale 0-54), GHQ-12 General Health Questionnaire (measure psychological problems)-12 questions (scale 0-12), QEEW Questionnaire on the Experienced and Evaluation of Work (scale 0-100), NfR need for recovery, Wp workpace, $M S$ mental strain

*Groups differ significantly with $\mathrm{p} \leq 0.05$

a 'Lifestyle-risk' indicates the risk of health problems due to unhealthy behavior

pace. Mental strain was reported high in all groups. Differences between groups are small and insignificant with large variations within groups. Observation of the lifestyle results show that in the group with normal-high HRV, $53.4 \%$ were not physically active enough, while in the group with very low HRV this was $45.7 \%$. Alcohol consumption and smoking were reported as a normal risk by most of the workers (more than $80 \%$ in all groups) and only $2.2 \%$ were classified in the high risk alcohol category. For the statistical comparison the moderate and high 
health risk of lifestyle factors were collapsed, to ensure cells were filled with more than five participants. Although some small differences in lifestyle were observed, these

Table 3 The correlation of raw MHRR with parameters of the WHA

\begin{tabular}{lccl}
\hline & \multicolumn{3}{l}{ Spearman's correlation } \\
\cline { 2 - 4 } & $\mathrm{R}$ & $\mathrm{SE}$ & $\mathrm{BCa} 95 \%$ (lower, upper) \\
\hline Age & $-0.44^{\mathrm{a}}$ & 0.03 & $-0.50,-0.38$ \\
Blood-pressure. systolic & $-0.22^{\mathrm{a}}$ & 0.03 & $-0.28,-0.15$ \\
Blood-pressure. diastolic & $-0.17^{\mathrm{a}}$ & 0.03 & $-0.23,-0.10$ \\
Cholesterol & $-0.18^{\mathrm{a}}$ & 0.03 & $-0.24,-0.12$ \\
Glucose & 0.02 & 0.03 & $-0.05,0.09$ \\
BMI & $-0.20^{\mathrm{a}}$ & 0.03 & $-0.26,-0.16$ \\
Waist circumference & $-0.21^{\mathrm{a}}$ & 0.03 & $-0.27,-0.15$ \\
WAI-short & $0.13^{\mathrm{a}}$ & 0.03 & $0.07,0.20$ \\
UBES-9 & 0.01 & 0.04 & $-0.06,0.08$ \\
GHQ-12 & -0.00 & 0.03 & $-0.07,0.07$ \\
QEEW-need for recovery & 0.00 & 0.04 & $-0.06,0.07$ \\
QEEW-workpace & 0.04 & 0.04 & $-0.03,0.11$ \\
QEEW-mental strain & 0.00 & 0.03 & $-0.06,0.07$ \\
Physical activity & $0.08^{\mathrm{a}}$ & 0.03 & $0.01,0.14$ \\
Smoking & -0.05 & 0.03 & $-0.12,0.02$ \\
Alcohol & $-0.10^{\mathrm{a}}$ & 0.04 & $-0.16,-0.02$ \\
Nutrition & 0.03 & 0.03 & $-0.04,0.10$ \\
Recreation & 0.04 & 0.03 & $-0.03,0.11$ \\
\hline
\end{tabular}

The $95 \%$ confidence interval is calculated with a bias-corrected and accelerated (BCa) bootstrap procedure (1000 samples)

$R$ correlation coefficient, $S E$ standard error, BMI Body Mass Index, $B C a$ bias-corrected and accelerated bootstrap, MHRR mean heart rate range, WAI-short Work Ability Index-short version, UWES-9 Utrecht Work Engagement Scale-9 questions, GHQ-12 General Health Questionnaire (measure: psychological problems)-12 questions, $Q E E W$ Questionnaire on the Experienced and Evaluation of Work

${ }^{\mathrm{a}} \mathrm{BCa} 95 \%$ does not cross 0 , indicating a significant correlation were statistically insignificant $(H(2)=3.37, p=0.20$ (recreation) to $H(2)=0.53, p=0.79$ (smoking)), including physical activity $(H(2)=1.51, p=0.48)$.

\section{Biometry}

Differences in biometry between groups were small. BMI was significantly different $(H(2)=7.22, p=0.03)$ and waist circumference was borderline significantly different $(H(2)=5.96, p=0.05)$ between groups. A post hoc Mann-Whitney U test revealed that only the very low HRV group (median $B M I=26.3$ ) differed significantly from the normal-high HRV (median $B M I=25.4$ ) group for BMI $(U=11140.5, z=-1.99, p=0.047)$. All groups on average were overweight.

\section{Correlations}

The continuous parameters were skewed and a non-parametric Spearman test was used. Correlation between RMSSD and MHRR was $r=0.66(p<0.01)$. Because the residuals did not meet the assumptions of homoscedasticity, the 95\% CI around $r$ was created with a robust Bias-Corrected and accelerated bootstrap procedure of 1000 samples (BCa 95\%). The Spearman correlation was small but significant for most of the biometry measures (diastolic and systolic blood-pressure, cholesterol, BMI, waist circumference), the workability index, physical activity, and alcohol consumption, but not for the other measures (Table 3). MHRR decreases when more physical activity is reported, the association with alcohol was negative. In line with previous literature (Almeida-Santos et al. 2016; Koenig et al. 2015), age and MHRR correlated $r=0.40(p<0.01)$ in our study, which confirms the necessity to control for age in the regression analyses (Table 4).
Table 4 Results of the linear regression analyses with a backward procedure

\begin{tabular}{|c|c|c|c|c|c|c|c|}
\hline \multirow{2}{*}{$\begin{array}{l}\text { Dependent } \\
\text { variable: } 10 \log \\
\text { (MHRR) }\end{array}$} & \multirow[t]{2}{*}{ Unstandardized B } & \multirow[t]{2}{*}{ Standardized B } & \multicolumn{2}{|c|}{$\mathrm{BCa} 95.0 \%$ for $\mathrm{B}$} & \multirow[t]{2}{*}{ SE } & \multirow[t]{2}{*}{ Sig. } & \multirow[t]{2}{*}{ VIF } \\
\hline & & & Lower bound & Upper bound & & & \\
\hline Constant & 2.28 & & 1.95 & 2.60 & 0.16 & 0.00 & \\
\hline Age & -0.009 & -0.418 & -0.011 & -0.008 & 0.001 & 0.00 & 1.04 \\
\hline $10 \log (\mathrm{BMI})$ & -0.45 & -0.11 & -0.67 & -0.21 & 0.12 & 0.00 & 1.05 \\
\hline Physical activity & 0.04 & 0.08 & 0.01 & 0.07 & 0.01 & 0.01 & 1.01 \\
\hline
\end{tabular}

MHRR mean heart rate range, Unstandardized B regression coefficient, SE standard error, Standardized B standardized regression coefficient, $B M I$ Body Mass Index, $B C a$ bias-corrected and accelerated bootstrap, $V I F=$ variance inflation factor

The 95\% confidence interval around B is calculated with a Bias-corrected and accelerated (BCa) bootstrap procedure (1000 samples). The final model with 3 independent parameters is presented. $\mathrm{R}^{2}=21.1 \%$, Adjusted $\mathrm{R}^{2}=20.8 \% F(3,876)=77.90, \mathrm{p} \leq 0.01$

Physical activity coding: $0=$ healthy physical active behavior, $1=$ moderate or unhealthy physical active behavior 


\section{Regression Analyses}

BMI, waist circumference, blood-pressure (systolic and diastolic), cholesterol, WAI, physical activity and alcohol consumption were entered in the linear regression model with the $\mathrm{BCa} 95 \%$ procedure, controlled for age. MHRR and biometry were $10 \log$-transformed. The WAI was treated as a continuous scale because dummy variables would be very uninterpretable with the wide scoring range (7-49) of the WAI. Reversed WAI data were $10 \log$-transformed.

In the first model the nine variables are not significantly associated with HRV when entered together. BMI and waistcircumference both showed VIF values greater than 3 and systolic and diastolic blood-pressure showed VIF values greater than 2, indicating collinearity. With the backward procedure, in each step the least significant variable is excluded from the model until a model is found with only significant contributing variables and acceptable collinearity. Appendix 2 shows all steps of the backward procedure.

In the final model (adjusted $\mathrm{R}^{2}=20.8 \%$ ) with only significant contributing variables, $21.1 \%$ of MHRR was explained by age, BMI and Physical activity. Physical activity was coded as zero for healthy physical activity behavior and one for moderate and unhealthy physical activity behavior. BMI appeared to be a better predictor for MHRR than waist circumference.

In the final model, MHRR was significantly lower in aging workers with a higher BMI and healthy physical behavior.

\section{Discussion}

The aim of this study was to explore associations between a novel compressed measure of HRV and other health related parameters, as a first step to studying the added value of HRV in a WHA. In this cross-sectional study, the very low HRV group was older and longer employed than the high HRV group. Because the classification was age corrected, a difference in age was remarkable. Although a forced breathing protocol was found to be a reliable and sensitive measure previously (Russoniello et al. 2013; Shields 2009), more studies in the occupational setting could contribute to stronger evidence for HRV reference values for age. Analyzing the raw MHRR data revealed significant univariate correlations between HRV and age, workability, blood pressure, cholesterol, BMI, waist circumference, physical activity and alcohol consumption. A high HRV was correlated to preferable health outcomes, except for physical activity. These results appear quite consistent with others (Almeida-Santos et al. 2016; Koenig et al. 2015) who also reported similar relations between HRV, age, and being overweight, although the strength of the associations may vary and the most dominant factors may differ [e.g. BMI in our study and waist circumference in others (Koenig et al. 2015)]. The result that HRV was lower when workers reported to be more physically active, controlled for age, was not expected. Others have reported that physical training had no or a positive effect on HRV on the long term (Amano et al. 2001; Jurca et al. 2004; Loimaala et al. 2000). In previous intervention studies (Amano et al. 2001; Jurca et al. 2004; Loimaala et al. 2000), exercise level was strictly controlled and, therefore, internal validity of these measurements is likely higher than internal validity of the self-report questionnaire in our study; Participants at risk may have provided preferable responses to our questionnaire regarding physical activity, biasing results. However, the observed association with physical activity was borderline significant and small and clinical relevance is questionable.

No significant association was observed between mental and psychological problems and MHRR. This result is not supported by others (Beauchaine and Thayer 2015; Geisler et al. 2013; Lennartsson et al. 2016; Thayer et al. 2009; Williams et al. 2015; Zahn et al. 2016), and might be attributed to floor and ceiling effects. In the current practical setting where predominantly healthy workers were assessed and prevalence of dysfunction in all the measured constructs was low, except for mental strain. This questionnaire however was not discriminative, since most workers scored very high on experienced mental strain (ceiling effect). With low prevalence and little variation, a significant association is less likely to be detected (Altman 1991).

We used MHRR as a measure for HRV because it is easier to explain to workers than the abstract time domain parameter RMSSD. However, RMSSD has been studied in most previous research examining correlations with psychological and mental problems (Beaumont et al. 2012; Geisler et al. 2013; Thayer et al. 2009; Williams et al. 2015; Zahn et al. 2016). In the current study, the correlation between RMSSD and MHRR was high $(r=0.66)$ and similar to other studies. The choice of MHRR as the HRV measure, therefore, is not expected to account for our lack of correlations observed. A post hoc study with RMSSD as dependent variable confirmed this assumption. To our knowledge this is only the second study (Russoniello et al. 2013) to examine MHRR assessed by a 1-minute deep paced-breathing protocol, and the first study in the context of WHA. More research would strengthen any conclusions.

The positioning of the lifestyle measures was different from the other measures. An unhealthy lifestyle is thought to precede health problems, while the other measures are already signs of a health risk. When a person has an unhealthy lifestyle, it is possible that the influence on the body and the autonomic nervous system is not yet measurable. Although we used the best available lifestyle questionnaires, these are not validated which limits our ability to draw strong conclusions. For example, reported alcohol consumption seemed to be very low in 
our high risk group (2.2\%), compared to previous studies of the general population [7.3\% (female)-10.4\% (male) heavy drinkers in the Netherlands in 2016 (RIVM 2017)]. This again could indicate preferable answering by our participants.

Although the cut-off values were in line with the finding in previous literature that a low HRV level is related to health risks (Dekker et al. 2000; Geisler et al. 2013; Lennartsson et al. 2016; Liao et al. 1998; Licht et al. 2013; Shaffer et al. 2014; Thayer and Lane 2007; Tsuji et al. 1996; Volker et al. 2016; Williams et al. 2015; Wulsin et al. 2016), the estimated cut-off values were not based on meaningful diagnostic outcomes. The protocol used is relatively new and the necessary data are not available for sustained employability yet. We used the categorization to describe group characteristics, which might have been different with other cut-off values based on ROC curves. The categorization was not used in correlation and multivariable analyses, and had, therefore, no influence on the main study results.

A general point of discussion is that we compared subjective self-report measures with the objective measure, HRV. Although others (Jarczok et al. 2015) reported a relationship between HRV and self-reported health, this was not confirmed in the current study. Previous research on other health and functioning aspects (Bieleman et al. 2009; Reneman et al. 2002) has shown that self-report and physical measures do not correlate well, even when they aim to measure the same construct. This would support the idea that HRV (MHRR) could measure a different aspect of risk for psychological and mental health than the questionnaires. A longitudinal design should be applied to study the value of HRV as a screener for health problems and sustained employability.

This is the first study to explore a 1-minute paced deepbreathing HRV protocol as an objective screening measure for multiple future health issues in a working population. A large sample was included, which enhances external validity. The WHA protocol content was based on expert knowledge but limited by practical restrictions such as time constraints within the OHS encounters. Although from a theoretical point of view this might not be ideal, it can be argued that this is the way it works in actual practice and our design contributes to external validity of results. On the other hand, selection bias cannot be ruled out. The employers invited the participants to the WHA. Participation rate was supplied by the OHS and non-response numbers were not available. In this study, the focus was limited to finding cross sectional relationships and therefore the predictive value of HRV for future health had to be studied in relation to other predictors, and not to an outcome of future health. Since we studied an apparently healthy population, low prevalence of actual health problems might account for the low correlations observed. With a longitudinal study and a health behavior outcome measure (sick-leave or sustained employability), the predictive value of HRV in a WHA can be studied and cut-off values could be determined for this particular goal.

In conclusion, this study with apparently healthy workers showed that the age controlled, very low HRV group was significantly older, employed longer, less educated, had a higher BMI and larger waist circumference than the group with normal-high HRV. A lower HRV was significantly associated with aging, higher measures of obesity (BMI), and with higher levels of reported physical activity, which provides a first glance of the utility of a 1-minute paced deep-breathing HRV protocol as part of a comprehensive preventive Workers' Health Assessment. Predictive validity of MHRR should be evaluated longitudinally as part of a screen for actual health outcomes. Based on this crosssectional study of the value of HRV assessed by a 1-minute paced deep-breathing protocol, caution has to be taken for individual decision making when using only MHRR as a screen for future health and sustained employability.

Acknowledgements We would like to thank the Occupational Health Suppliers (Immens Advies and TIGRA) and workers for participating in the study.

Author Contributions RS, HJB, WMCSD, FGJO, DG, MFR contributed to the conception and design of the study. WMCSD, RS, FGJO and HJB performed the data-processing and statistical analyses. WMCSD wrote the manuscript. RS, HJB, RMcC, FGJO, DG, MFR, and WMCSD revised and commented on the whole manuscript. All authors read and approved the final manuscript.

Funding This study was funded by Expertise Center Tech for Future in The Netherlands (TFF150101 SHIFT). The funding source had no involvement in de study design, data collection, analysis or interpretation, in the writing of the report of decision to submit the article for publication.

\section{Compliance with Ethical Standards}

Conflict of interest $\mathrm{RMcC}$ works for HeartMath Research Centre, a non-profit organization. $\mathrm{RMcC}$ is a member of the scientific advisory board of HeartMath Institute who distributes the emWave Pro Plus ${ }^{\circledR}$ software. WMCSD, HJB, RS, FGJO, DG, MFR declare that they have no conflicts of interest.

Informed Consent All procedures followed were in accordance with the ethical standards of the responsible committee on human experimentation (institutional and national) and with the Helsinki Declaration of 1975, as revised in 2000 (5). Informed consent was obtained from all participants for being included in the study.

Open Access This article is distributed under the terms of the Creative Commons Attribution 4.0 International License (http://creativeco mmons.org/licenses/by/4.0/), which permits unrestricted use, distribution, and reproduction in any medium, provided you give appropriate credit to the original author(s) and the source, provide a link to the Creative Commons license, and indicate if changes were made. 


\section{Appendix 1}

See Table 5 .

Table 5 Cut off values of the questionnaires, which are described in the methods section of the text

\begin{tabular}{|c|c|c|c|}
\hline Cut off points & Not at risk (0 points) & Moderate risk (1 point) & High risk (2 points) \\
\hline Activity & $\begin{array}{l}\text { At least } 5 \text { days per week for } 30 \text { min low } \\
\text { intensity activity AND at least } 2 \text { days per } \\
\text { week } 20 \text { min. intensive active }\end{array}$ & $\begin{array}{l}\text { At least } 5 \text { days a week } 30 \mathrm{~min} \text {. low } \\
\text { intensity activity } \\
\text { OR } \\
\text { At least } 2 \text { days per week } 20 \mathrm{~min} \text {. } \\
\text { intensive active }\end{array}$ & $\begin{array}{l}\text { Less than } 5 \text { days per week } 30 \text { min. low inten- } \\
\text { sity activity } \\
\text { AND } \\
\text { Less than } 2 \text { days per week } 20 \text { min. intensive } \\
\text { active }\end{array}$ \\
\hline Smoking & Non-smoker & $\begin{array}{l}\leq 2 \text { days per week in combinations } \\
\text { with } \leq 10 \text { cigarettes per day }\end{array}$ & $\begin{array}{l}\geq 3 \text { days per week or } \\
\leq 2 \text { days per week in combinations with } \geq 10 \\
\text { cigarettes per day }\end{array}$ \\
\hline Alcohol & $\begin{array}{l}\leq 5 \text { days per week and } \\
\leq 15 \text { drinks per week }\end{array}$ & $\begin{array}{l}>5 \text { days per week and } \\
\leq 15 \text { drinks per week } \\
\text { OR } \\
\leq 5 \text { days per week } \\
>15 \text { drinks per week }\end{array}$ & $\begin{array}{l}>5 \text { days per week and } \\
>15 \text { drinks per week }\end{array}$ \\
\hline Nutrition & $\begin{array}{l}\text { Nutrition behavior without undesirable } \\
\text { attitude as mentioned at moderate and } \\
\text { high risk }\end{array}$ & $\begin{array}{l}\leq 4 \text { days per week } 3 \text { meals } \\
\text { or } \\
\leq 4 \text { days per week } 200 \text { gr vegetables }\end{array}$ & $\begin{array}{l}\leq 1 \text { day, week } 3 \text { meals } \\
\text { and/or } \\
\leq 1 \text { day, week } 200 \mathrm{~g} \text { vegetables } \\
\text { and/or } \\
\leq 4 \text { days, week } 3 \text { meals plus } \leq 4 \text { days, week } \\
200 \text { g vegetables }\end{array}$ \\
\hline Recreation & \multicolumn{3}{|c|}{ Higher score $=$ higher risk score is proprietary for OHS } \\
\hline UWES-9 & $26-54$ & $16-25$ & $0-15$ \\
\hline WAI-short & $37-49$ & $28-36$ & $7-27$ \\
\hline GHQ-12 & $0-3$ & & $>3$ \\
\hline QEEW-NfR & Scale 1-100: higher score $=$ higher risk & & \\
\hline QEEW-Wp & Scale 1-100: higher score $=$ higher risk & & \\
\hline QEEW-MS & Scale 1-100: higher score $=$ higher risk & & \\
\hline
\end{tabular}

WAI Work Ability Index-short version, UWES-9 Utrecht Work Engagement Scale-9 questions, GHQ-12 General Health Questionnaire (measure psychological problems)-12 questions, $Q E E W$ Questionnaire on the Experienced and Evaluation of Work, NfR need for recovery (11 questions), $W p$ workpace (11 questions), $M S$ mental strain (9 questions)

\section{Biometry}

\section{Measurement information}

- HRV: see article text.

- BMI: bodyweight $(\mathrm{kg}) /$ bodylength $^{2}(\mathrm{~m})$

- Waist circumference: Participant stands upright, measure is taken of waist circumference at bellybutton level (in $\mathrm{cm}$ ) while participant breathes out normally.

- Cholesterol: finger-stick total cholesterol measurement. In mmol per 1.

- Glucose: finger-stick glucose measurement. In mmol per 1 .

- Blood pressure: participant is instructed not to perform heavy work at least $45 \mathrm{~min}$ prior to the measurement. Participant is sitting in slightly reclined position. Blood pressure is measured with a non-invasive automated measurement device.
See Table 6.

Table 6 Cutoff values of biometry

\begin{tabular}{llll}
\hline Normative values & Not at risk & Moderate risk & High risk \\
\hline BMI & $\leq 25.0$ & $25.1-29.9$ & $\geq 30.0$ \\
Waist circumference & & & \\
$\quad$ Female & $<80 \mathrm{~cm}$ & $80-88 \mathrm{~cm}$ & $>88 \mathrm{~cm}$ \\
$\quad$ Male & $<94 \mathrm{~cm}$ & $94-102 \mathrm{~cm}$ & $>102 \mathrm{~cm}$ \\
Cholesterol & $<5$ & $5,0-7,8$ & $<7,8$ \\
Glucose & $<7,8$ & $7,8-11$ & $>11$ \\
Systolic blood pressure & & & \\
18-60 years & $<140$ & $140-160$ & $>160$ \\
$>60$ years & $<145$ & $145-160$ & $>160$ \\
Diastolic blood pressure & $<90$ & $90-100$ & $>100$ \\
\hline
\end{tabular}

BMI Body Mass Index 


\section{Appendix 2}

See Table 7.

Table 7 Results of the linear regression analyses with a backward procedure; MHRR is the dependent variable and nine variables of the workers health assessment are the independent variables

\begin{tabular}{|c|c|c|c|c|c|c|c|}
\hline \multirow[t]{2}{*}{ Dependent variable: $10 \log (\mathrm{MHRR})$} & \multirow[t]{2}{*}{ Unstandardized B } & \multirow[t]{2}{*}{ Standardized B } & \multicolumn{2}{|c|}{$\mathrm{BCa} 95.0 \%$ for $\mathrm{B}$} & \multirow[t]{2}{*}{ SE } & \multirow[t]{2}{*}{ Sig. } & \multirow[t]{2}{*}{ VIF } \\
\hline & & & Lower bound & Upper bound & & & \\
\hline \multicolumn{8}{|c|}{ Step 1 (nine independent variables): $R^{2}=21.7 \%$, adjusted $R^{2}=20.7 \%, F(11,865)=21.78, p \leq 0.01$} \\
\hline Constant* & 2.22 & & 1.53 & 2.92 & 0.36 & 0.00 & \\
\hline Age* & -0.009 & -0.399 & -0.011 & -0.007 & 0.001 & 0.00 & 1.33 \\
\hline $10 \log (\mathrm{BMI})^{*}$ & -0.53 & -0.14 & -0.97 & -0.11 & 0.23 & 0.02 & 3.60 \\
\hline Dummy1_PhysAct & 0.02 & 0.05 & -0.03 & 0.08 & 0.03 & 0.39 & 3.74 \\
\hline Dummy2_PhysAct & 0.02 & 0.04 & -0.03 & 0.07 & 0.03 & 0.44 & 3.77 \\
\hline Dummy1_Alc & -0.02 & -0.03 & -0.06 & 0.03 & 0.02 & 0.45 & 1.22 \\
\hline Dummy2_Alc & 0.01 & 0.01 & -0.12 & 0.15 & 0.07 & 0.81 & 1.20 \\
\hline 10log (blood pressure diastolic) & -0.21 & -0.05 & -0.56 & 0.13 & 0.18 & 0.23 & 2.09 \\
\hline 10log (blood pressure systolic) & 0.13 & 0.03 & -0.20 & 0.47 & 0.17 & 0.44 & 2.01 \\
\hline $10 \log$ (waist circumference) & 0.20 & 0.05 & -0.30 & 0.65 & 0.25 & 0.44 & 3.81 \\
\hline $10 \log$ (cholesterol) & -0.10 & -0.04 & -0.25 & 0.08 & 0.08 & 0.23 & 1.15 \\
\hline $10 \log ($ reversed WAI +1$)$ & -0.03 & -0.04 & -0.08 & 0.02 & 0.03 & 0.23 & 1.09 \\
\hline \multicolumn{8}{|c|}{ Step 2 (Alcohol_dummy2 excluded): $\mathrm{R}^{2}=21.7 \%$, adjusted $\mathrm{R}^{2}=20.8 \%, \mathrm{~F}(10,866)=23.98, \mathrm{p} \leq 0.01$} \\
\hline Constant* & 2.21 & & 1.51 & 2.95 & 0.36 & 0.00 & \\
\hline Age* & -0.009 & -0.399 & -0.010 & -0.007 & 0.001 & 0.00 & 1.33 \\
\hline $10 \log (\mathrm{BMI})^{*}$ & -0.54 & -0.14 & -1.02 & -0.10 & 0.23 & 0.03 & 3.58 \\
\hline Dummy1_PhysAct & 0.02 & 0.05 & -0.03 & 0.07 & 0.03 & 0.33 & 3.71 \\
\hline Dummy2_PhysAct & 0.02 & 0.04 & -0.03 & 0.07 & 0.02 & 0.45 & 3.75 \\
\hline Dummy1_Alc & -0.02 & -0.02 & -0.06 & 0.03 & 0.02 & 0.52 & 1.05 \\
\hline 10log (blood pressure diastolic) & -0.21 & -0.05 & -0.56 & 0.14 & 0.18 & 0.24 & 2.09 \\
\hline $10 \log$ (blood pressure systolic) & 0.13 & 0.03 & -0.19 & 0.44 & 0.16 & 0.45 & 2.01 \\
\hline $10 \log$ (waist circumference) & 0.21 & 0.05 & -0.29 & 0.74 & 0.26 & 0.43 & 3.79 \\
\hline $10 \log$ (cholesterol) & -0.10 & -0.04 & -0.26 & 0.07 & 0.08 & 0.26 & 1.15 \\
\hline $10 \log ($ reversed WAI + 1) & -0.03 & -0.04 & -0.08 & 0.02 & 0.02 & 0.20 & 1.09 \\
\hline \multicolumn{8}{|c|}{ Step 3 (Dummy2_PhysAct excluded): $\mathrm{R}^{2}=21.6 \%$, adjusted $\mathrm{R}^{2}=20.8 \%, \mathrm{~F}(9,867)=26.60, \mathrm{p} \leq 0.01$} \\
\hline Constant* & 2.21 & & 1.50 & 2.93 & 0.37 & 0.00 & \\
\hline Age* & -0.009 & -0.399 & -0.011 & -0.007 & 0.001 & 0.00 & 1.33 \\
\hline $10 \log (\mathrm{BMI})^{*}$ & -0.53 & -0.14 & -0.96 & -0.08 & 0.23 & 0.02 & 3.58 \\
\hline Dummy1_PhysAct* & 0.04 & 0.09 & 0.01 & 0.07 & 0.01 & 0.01 & 1.04 \\
\hline Dummy1_Alc & -0.02 & -0.02 & -0.06 & 0.03 & 0.02 & 0.51 & 1.05 \\
\hline 10log (blood pressure diastolic) & -0.21 & -0.05 & -0.56 & 0.15 & 0.19 & 0.27 & 2.09 \\
\hline $10 \log$ (blood pressure systolic) & 0.12 & 0.03 & -0.23 & 0.44 & 0.17 & 0.49 & 2.00 \\
\hline $10 \log$ (waist circumference) & 0.21 & 0.05 & -0.27 & 0.72 & 0.26 & 0.41 & 3.79 \\
\hline $10 \log$ (cholesterol) & -0.10 & -0.04 & -0.26 & 0.07 & 0.08 & 0.25 & 1.15 \\
\hline $10 \log ($ reversed WAI + 1) & -0.03 & -0.04 & -0.08 & 0.02 & 0.02 & 0.23 & 1.08 \\
\hline \multicolumn{8}{|c|}{ Step 4 (10log (blood pressure systolic) excluded): $R^{2}=21.6 \%$, adjusted $R^{2}=20.9 \%, F(8,868)=29.90, p \leq 0.01$} \\
\hline Constant* & 2.30 & & 1.59 & 2.95 & 0.35 & 0.00 & \\
\hline Age* & -0.009 & -0.397 & -0.010 & -0.007 & 0.001 & 0.00 & 1.32 \\
\hline $10 \log (\mathrm{BMI})^{*}$ & -0.53 & -0.14 & -0.97 & -0.09 & 0.23 & 0.02 & 3.58 \\
\hline Dummy1_PhysAct* & 0.04 & 0.08 & 0.01 & 0.07 & 0.01 & 0.01 & 1.03 \\
\hline Dummy1_Alc & -0.01 & -0.02 & -0.06 & 0.03 & 0.02 & 0.49 & 1.05 \\
\hline 10log (blood pressure diastolic) & -0.13 & -0.03 & -0.42 & 0.17 & 0.15 & 0.37 & 1.27 \\
\hline
\end{tabular}


Table 7 (continued)

\begin{tabular}{|c|c|c|c|c|c|c|c|}
\hline \multirow[t]{2}{*}{ Dependent variable: $10 \log (\mathrm{MHRR})$} & \multirow[t]{2}{*}{ Unstandardized B } & \multirow[t]{2}{*}{ Standardized B } & \multicolumn{2}{|c|}{$\mathrm{BCa} 95.0 \%$ for $\mathrm{B}$} & \multirow[t]{2}{*}{ SE } & \multirow[t]{2}{*}{ Sig. } & \multirow[t]{2}{*}{ VIF } \\
\hline & & & Lower bound & Upper bound & & & \\
\hline $10 \log$ (waist circumference) & 0.22 & 0.05 & -0.25 & 0.69 & 0.24 & 0.37 & 3.78 \\
\hline $10 \log$ (cholesterol) & -0.10 & -0.04 & -0.27 & 0.06 & 0.08 & 0.23 & 1.15 \\
\hline $10 \log ($ reversed WAI + 1) & -0.03 & -0.04 & -0.08 & 0.01 & 0.02 & 0.20 & 1.07 \\
\hline \multicolumn{8}{|c|}{ Step 5 (Dummy1_Alcohol excluded). $R^{2}=21.6 \%$, adjusted $R^{2}=20.9 \%, F(7,869)=34.12, p \leq 0.01$} \\
\hline Constant* & 2.32 & & 1.59 & 3.06 & 0.36 & 0.00 & \\
\hline Age* & -0.009 & -0.398 & -0.010 & -0.007 & 0.001 & 0.00 & 1.31 \\
\hline $10 \log (\mathrm{BMI})^{*}$ & -0.52 & -0.13 & -0.98 & -0.10 & 0.23 & 0.02 & 3.56 \\
\hline Dummy1_PhysAct* & 0.04 & 0.08 & 0.01 & 0.06 & 0.01 & 0.01 & 1.03 \\
\hline 10log (blood pressure diastolic) & -0.13 & -0.03 & -0.43 & 0.15 & 0.15 & 0.36 & 1.27 \\
\hline $10 \log$ (waist circumference) & 0.20 & 0.05 & -0.29 & 0.68 & 0.26 & 0.44 & 3.74 \\
\hline $10 \log$ (cholesterol) & -0.10 & -0.04 & -0.26 & 0.05 & 0.08 & 0.19 & 1.14 \\
\hline $10 \log ($ reversed WAI + 1) & -0.03 & -0.04 & -0.08 & 0.02 & 0.03 & 0.22 & 1.07 \\
\hline \multicolumn{8}{|c|}{ Step $6\left(10 \log\right.$ (waist circumference) excluded). $R^{2}=21.5 \%$, adjusted $R^{2}=21.0 \%, F(6.870)=39.72, p \leq 0.01$} \\
\hline Constant* & 2.49 & & 1.96 & 3.06 & 0.28 & 0.00 & \\
\hline Age* & -0.009 & -0.392 & -0.010 & -0.007 & 0.001 & 0.00 & 1.24 \\
\hline $10 \log (\mathrm{BMI})^{*}$ & -0.38 & -0.10 & -0.63 & -0.10 & 0.13 & 0.01 & 1.18 \\
\hline Dummy1_PhysAct* & 0.04 & 0.09 & 0.01 & 0.07 & 0.01 & 0.00 & 1.02 \\
\hline 10log (blood pressure diastolic) & -0.13 & -0.03 & -0.43 & 0.16 & 0.15 & 0.37 & 1.26 \\
\hline $10 \log$ (cholesterol) & -0.10 & -0.04 & -0.25 & 0.05 & 0.08 & 0.17 & 1.14 \\
\hline $10 \log ($ reversed WAI +1$)$ & -0.03 & -0.04 & -0.08 & 0.02 & 0.02 & 0.19 & 1.07 \\
\hline \multicolumn{8}{|c|}{ Step 7 (10log (blood pressure diastolic) excluded). $R^{2}=21.4 \%$, adjusted $R^{2}=21.0 \%, F(5.871)=47.52, p \leq 0.01$} \\
\hline Constant* & 2.31 & & 1.98 & 2.59 & 0.16 & 0.00 & \\
\hline Age* & -0.009 & -0.400 & -0.010 & -0.007 & 0.001 & 0.00 & 1.15 \\
\hline $10 \log (\mathrm{BMI})^{*}$ & -0.41 & -0.10 & -0.63 & -0.16 & 0.12 & 0.00 & 1.08 \\
\hline Dummy1_PhysAct* & 0.04 & 0.08 & 0.01 & 0.07 & 0.01 & 0.01 & 1.01 \\
\hline $10 \log$ (cholesterol) & -0.11 & -0.04 & -0.26 & 0.05 & 0.08 & 0.17 & 1.13 \\
\hline 10log (WAI-reversed) & -0.03 & -0.04 & -0.08 & 0.02 & 0.03 & 0.22 & 1.07 \\
\hline \multicolumn{8}{|c|}{ Step $8(10 \log ($ reversed WAI +1$))$ excluded $) . R^{2}=21.3 \%$, adjusted $R^{2}=20.9 \%, F(4.872)=59.01, p \leq 0.01$} \\
\hline Constant* & 2.31 & & 2.01 & 2.63 & 0.16 & 0.00 & \\
\hline Age* & -0.009 & -0.406 & -0.010 & -0.007 & 0.001 & 0.00 & 1.12 \\
\hline $10 \log (\mathrm{BMI})^{*}$ & -0.42 & -0.11 & -0.66 & -0.19 & 0.12 & 0.00 & 1.07 \\
\hline Dummy1_PhysAct* & 0.04 & 0.08 & 0.01 & 0.06 & 0.01 & 0.01 & 1.01 \\
\hline $10 \log ($ cholesterol) & -0.12 & -0.05 & -0.27 & 0.03 & 0.08 & 0.13 & 1.12 \\
\hline \multicolumn{8}{|c|}{ Step $9\left(10 \log\right.$ (cholesterol) excluded). $R^{2}=21.1 \%$, adjusted $R^{2}=20.8 \%, F(3.873)=77.90, p \leq 0.01$} \\
\hline Constant* & 2.28 & & 1.95 & 2.60 & 0.16 & 0.00 & \\
\hline Age* & -0.009 & -0.418 & -0.011 & -0.008 & 0.001 & 0.00 & 1.04 \\
\hline $10 \log (\mathrm{BMI})^{*}$ & -0.45 & -0.11 & -0.67 & -0.21 & 0.12 & 0.00 & 1.05 \\
\hline Dummy1_PhysAct* & 0.04 & 0.08 & 0.01 & 0.07 & 0.01 & 0.01 & 1.01 \\
\hline
\end{tabular}

If relevant, data are transformed to meet the assumption of a normal distribution. The $95 \%$ confidence interval around $\mathrm{B}$ is calculated with a bias-corrected and accelerated (BCa) bootstrap procedure (1000 samples)

MHRR Mean Heart Rate Range, Unstandardized B regression coefficient, SE standard error, Standardized B Standardized regression coefficient, $B M I$ Body Mass Index, BCa bias-corrected and accelerated bootstrap, VIF variance inflation factor

Dummy1_PhysAct: $0=$ healthy physical active behavior, $1=$ moderate or unhealthy physical active behavior. Dummy 2 PhysAct: $0=$ healthy or moderate active behavior, $1=$ unhealthy physical active behavior. Dummy $1 \_$Alc: $0=$ healthy alcohol consumption, $1=$ moderate or unhealthy alcohol consumption. Dummy2_Alc: $0=$ healthy or moderate alcohol consumption, $1=$ unhealthy alcohol consumption

*Significant: $\mathrm{p}<0.05$ and $95 \% \mathrm{BCa}$ did not cross zero 


\section{References}

Alavinia, S. M., de Boer, A. G., van Duivenbooden, J. C., FringsDresen, M. H., \& Burdorf, A. (2009). Determinants of work ability and its predictive value for disability. Occupational Medicine (London), 59(1), 32-37. https://doi.org/10.1093/occmed/kqn148.

Aldana, S. G., Merrill, R. M., Price, K., Hardy, A., \& Hager, R. (2005). Financial impact of a comprehensive multisite workplace health promotion program. Preventive Medicine, 40(2), 131-137. https ://doi.org/10.1016/j.ypmed.2004.05.008.

Almeida-Santos, M. A., Barreto-Filho, J. A., Oliveira, J. L., Reis, F. P., da Cunha Oliveira, C. C., \& Sousa, A. C. (2016). Aging, heart rate variability and patterns of autonomic regulation of the heart. Archives of Gerontology and Geriatrics, 63, 1-8. https://doi. org/10.1016/j.archger.2015.11.011.

Altman, D. G. (1991). Practical statistics for medical research (1st edn.). London: Chapman \& Hall.

Amano, M., Kanda, T., Ue, H., \& Moritani, T. (2001). Exercise training and autonomic nervous system activity in obese individuals. Medicine \& Science in Sports \& Exercise, 33(8), 1287-1291.

Beauchaine, T. P., \& Thayer, J. F. (2015). Heart rate variability as a transdiagnostic biomarker of psychopathology. International Journal of Psychophysiology, $98(2$ Pt 2), 338-350. https://doi. org/10.1016/j.ijpsycho.2015.08.004.

Beaumont, A., Burton, A. R., Lemon, J., Bennett, B. K., Lloyd, A., \& Vollmer-Conna, U. (2012). Reduced cardiac vagal modulation impacts on cognitive performance in chronic fatigue syndrome. PLoS ONE, 7(11), e49518. https://doi.org/10.1371/journ al.pone.0049518.

Bieleman, H. J., Reneman, M. F., van Ittersum, M. W., van der Schans, C. P., Groothoff, J. W., \& Oosterveld, F. G. (2009). Self-reported functional status as predictor of observed functional capacity in subjects with early osteoarthritis of the hip and knee: A diagnostic study in the CHECK cohort. Journal of Occupational Rehabilitation, 19(4), 345-353. https://doi. org/10.1007/s10926-009-9189-9.

De Zwart, B. C., Frings-Dresen, M. H., \& van Duivenbooden, J. C. (2002). Test-retest reliability of the Work Ability Index questionnaire. Occupational Medicine (London), 52(4), 177-181.

Dekker, J. M., Crow, R. S., Folsom, A. R., Hannan, P. J., Liao, D., Swenne, C. A., \& Schouten, E. G. (2000). Low heart rate variability in a 2-minute rhythm strip predicts risk of coronary heart disease and mortality from several causes: The ARIC Study: Atherosclerosis Risk in Communities. Circulation, 102(11), 1239-1244.

Douwes, M., Hooftman, M., Kraan, K., Steenbeek, R., Venema, A., de Vroome, E., Eysink, P., van der Molen, H., Frings-Dresen, M., \& van de Bossche, S. (2014). Arbobalans 2014. Leiden: TNO. Retrieved October 12, 2018, from https://www.monitorarbeid. tno.nl/dynamics/modules/SPUB0102/view.php?pub_Id=10029 0\&att_Id $=4911$.

Geisler, F. C. M., Kubiak, T., Siewert, K., \& Weber, H. (2013). Cardiac vagal tone is associated with social engagement and selfregulation. 93(2), 279-286. https://doi.org/10.1016/j.biops ycho.2013.02.013.

Ilmarinen, J. (2009). Work ability-A comprehensive concept for occupational health research and prevention. Scandinavian Journal of Work, Environment \& Health, 35(1), 1-5.

Jarczok, M. N., Kleber, M. E., Koenig, J., Loerbroks, A., Herr, R. M., Hoffmann, K., Fischer, J. E., Benyamini, Y., \& Thayer, J. F. (2015). Investigating the associations of self-rated health: Heart rate variability is more strongly associated than inflammatory and other frequently used biomarkers in a cross sectional occupational sample. PLoS ONE. https://doi.org/10.1371/jounal.pone.0117196.

Jurca, R., Church, T. S., Morss, G. M., Jordan, A. N., \& Earnest, C. P. (2004). Eight weeks of moderate-intensity exercise training increases heart rate variability in sedentary postmenopausal women. American Heart Journal, 147(5), e21. https://doi. org/10.1016/j.ahj.2003.10.024.

Koenig, J., Windham, B. G., Ferrucci, L., Sonntag, D., Fischer, J. E., Thayer, J. F., \& Jarczok, M. N. (2015). Association strength of three adiposity measures with autonomic nervous system function in apparently healthy employees. The Journal of Nutrition Health and Aging, 19(9), 879-882. https://doi.org/10.1007/s1260 3-015-0508-x.

Koeter, M. W. J., \& Ormel, J. (1991). General Health Questionnaire, Nederlandse bewerking. Lisse: Handleiding.

Leijten, F. R., van den Heuvel, S. G., Ybema, J. F., van der Beek, A. J., Robroek, S. J., \& Burdorf, A. (2014). The influence of chronic health problems on work ability and productivity at work: A longitudinal study among older employees. Scandinavian Journal of Work, Environment \& Health, 40(5), 473-482. https://doi. org/10.5271/sjweh.3444.

Lennartsson, A. K., Jonsdottir, I., \& Sjörs, A. (2016). Low heart rate variability in patients with clinical burnout. International Journal of Psychophysiology, 110, 171-178.

Liao, D., Sloan, R. P., Cascio, W. E., Folsom, A. R., Liese, A. D., Evans, G. W., Cai, J., \& Sharrett, A. R. (1998). Multiple metabolic syndrome is associated with lower heart rate variability. The Atherosclerosis Risk in Communities Study. Diabetes Care, 21(12), 2116-2122.

Licht, C. M., de Geus, E. J., \& Penninx, B. W. (2013). Dysregulation of the autonomic nervous system predicts the development of the metabolic syndrome. The Journal of Clinical Endocrinology \& Metabolism, 98(6), 2484-2493. https://doi.org/10.1210/ jc.2012-3104

Loimaala, A., Huikuri, H., Oja, P., Pasanen, M., \& Vuori, I. (2000). Controlled 5-mo aerobic training improves heart rate but not heart rate variability or baroreflex sensitivity. Journal of Applied Physiology (1985), 89(5), 1825-1829.

McCraty, R., Barrios-Choplin, B., Rozman, D., Atkinson, M., \& Watkins, A. D. (1998). The impact of a new emotional self-management program on stress, emotions, heart rate variability, DHEA and cortisol. Integrative Psychological and Behavioral Science, 33(2), 151-170

Perosh. (2014). Position paper 3-Health, demographic changes and wellbeing: Occupational safety and health in the context of demographic change. Retrieved December 14, 2017, from https ://osha.europa.eu/en/position-paper3-osh-in-context-of-demog raphic-change.

Radkiewitz, P., \& Widerszal-Bazyl, M. (2005, June 20). Psychometric properties of Work Ability Index in the light of comparative survey study. In: International Congress Series, vol. 1280, pp. 304-309.

Reeuwijk, K. G., Robroek, S. J. W., Niessen, M. A. J., Kraaijenhagen, R. A., Vergouwe, Y., \& Burdorf, A. (2015). The prognostic value of the Work Ability Index for sickness absence among office workers. PLOS ONE, 10(5), e0126969-e0126969. https:// doi.org/10.1371/journal.pone.0126969.

Reneman, M. F., Jorritsma, W., Schellekens, J. M., \& Goeken, L. N. (2002). Concurrent validity of questionnaire and performancebased disability measurements in patients with chronic nonspecific low back pain. Journal of Occupational Rehabilitation, 12(3), 119-129.

RIVM. (2016). Nationaal Zorgkompas. van https://www.volksgezon dheidenzorg.info.

RIVM (2017). Alcoholgebruik | Cijfers \& Context | Huidige situatie | Volksgezondheidenzorg.info. Retrieved December 14, 2017, from https://www.volksgezondheidenzorg.info/onderwerp/alcoholgeb ruik/cijfers-context/huidige-situatie\#node-alcoholgebruik-volwa ssenen. 
Russoniello, C. V., Zhirnov, Y. N., Pougatchev, V. I., \& Gribkov, E. N. (2013). Heart rate variability and biological age: Implications for health and gaming. Cyberpsychology, Behavior, and Social Networking, 16(4), 302-308. https://doi.org/10.1089/cyber .2013.1505.

Sas, K., \& Suarez, A. (2014). Priorities for occupational safety and health research in Europe for the year 2013-2020. In EU-OSHA (Red.). Luxembourg: Publications Office of the European Union. Retrieved October 11, 2018, from https://osha.europa.eu/en/tools -and-publications/publications/reports/priorities-for-occupation al-safety-and-health-research-in-europe-2013-2020/view/.

Schaufeli, W. B., Arnold, B. B., \& Salanova, M. (2006). The measurement of work engagement with a short questionnaire-a crossnational study. Educational and Psychological Management, 66(4), 701-716. https://doi.org/10.1177/0013164405282471.

Schaufeli, W. B., \& Bakker, A. B. (2003). Test manual for the Utrecht Work Engagement Scale. The Netherlands: Utrecht University. Retrieved December 14, 2017, from http://www.schaufeli.com.

Shaffer, F., McCraty, R., \& Zerr, C. L. (2014). A healthy heart is not a metronome: An integrative review of the heart's anatomy and heart rate variability. Frontiers in Psychology. https://doi. org/10.3389/fpsyg.2014.01040.

Shields, R. W. Jr. (2009). Heart rate variability with deep breathing as a clinical test of cardiovagal function. Cleve Clinical Journal of Medicine, 76(Suppl 2), S37-S40. https://doi.org/10.3949/ccjm.76. s2.08.

Sluiter, J. K., \& Hulshof, C. T. J. (2013). Hulpdocument voor bedrijfsartsen bij de ontwikkeling en uitvoering van preventief medisch onderzoek bij werkenden. (translation: Guide for occupational physicians for developing and applying a preventive medical exam for workers). Amsterdam, Netherlands.

Soer, R., van der Schans, C. P., Geertzen, J. H., Groothoff, J. W., Brouwer, S., Dijkstra, P. U., \& Reneman, M. F. (2009). Normative Values for a Functional Capacity Evaluation. Archives of Physical Medicine and Rehabilitation, 90(10), 1785-1794. https://doi. org/10.1016/j.apmr.2009.05.008.

Task Force of the European Society of Cardiology and the North American Society of Pacing and Electrophysiology. (1996). Heart rate variability: Standards of measurement, physiological interpretation and clinical use. Circulation, 93(5), 1043-1065.

Thayer, J. F., Hansen, A. L., Saus-Rose, E., \& Johnsen, B. H. (2009). Heart rate variability, prefrontal neural function, and cognitive performance: The neurovisceral integration perspective on selfregulation, adaptation, and health. Annals of Behavioral Medicine, 37(2), 141-153. https://doi.org/10.1007/s12160-009-9101-z.

Thayer, J. F., \& Lane, R. D. (2007). The role of vagal function in the risk for cardiovascular disease and mortality. Biological Psychology, 74(2), 224-242. https://doi.org/10.1016/j.biops ycho.2005.11.013.

Tsuji, H., Larson, M. G., Venditti, F. J., Manders, E. S., Evans, J. C., Feldman, C. L., \& Levy, D. (1996). Impact of reduced heart rate variability on risk for cardiac events: The Framingham Heart Study. Circulation, 94(11), 2850-2855.

Tuomi, K., Ilmarinen, J., Jahkola, A., Katajarinne, L., Tulkki, A., Katajarinne, L., \& Tulkki, A. S. R. a. R. Pietiläinen (Red.) (1998). Work Ability Index (2nd druk Vol. 19). Helsinki: FIOD.

Tuomi, K., Vanhala, S., Nykyri, E., \& Janhonen, M. (2004). Organizational practices, work demands and the well-being of employees:
A follow-up study in the metal industry and retail trade. Occupational Medicine (London), 54(2), 115-121.

Umetani, K., Singer, D. H., McCraty, R., \& Atkinson, M. (1998). Twenty-four hour time domain heart rate variability and heart rate: Relations to age and gender over nine decades. Journal of the American College of Cardiology, 31(3), 593-601.

van Duin, C., \& Stoeldraijer, L. (2013). Bevolkingsprognose 20122060: Langer leven, langer werken. In CBS (ed.), Bevolkingstrends 2013: CBS. Retrieved October 12, 2018, from https:// www.cbs.nl/nl-nl/achtergrond/2013/47/bevolkingsprognose-20122060-langer-leven-langer-werken.

van Holland, B. J., Soer, R., de Boer, M. R., Reneman, M. F., \& Brouwer, S. (2015). Workers' health surveillance in the meat processing industry: Work and health indicators associated with work ability. Journal of Occupational Rehabilitation, 25(3), 618-626. https://doi.org/10.1007/s10926-015-9569-2.

Veldhoven, M., Meijman, T. F., Broersen, J. P. J., \& Fortuim, R. J. (2002). Handleiding VBBA (2nd druk). Amsterdam: SKB Vragenlijst Services.

Volker, I., Kirchner, C., \& Bock, O. L. (2016). Relation between multiple markers of work-related fatigue. Safety and Health at Work, $7(2), 124-129$.

Volksgezondheidenzorg.info. (2017) Ziekteverzuim I Cijfers \& Context I Huidige situatie I Volksgezondheidenzorg.info. RIVM. Retrieved December 14, 2017, from https://www.volksgezondheidenzor g.info/onderwerp/ziekteverzuim/cijfers-context/huidige-situa tie\#!node-ziektespecifiek-verzuim-naar-leeftijd.

Weel, A. N. H., Duijn, J. C. M., \& van Vliet, C. (2007). Preventief Medisch Onderzoek van werkenden: de Nederlandse vertaling van Workers'. Health Surveillance. TBVG, 15(2), 73-79. https://doi. org/10.1007/BF03074513.

WHO Regional Office of Europe (2002). Good practice in occupational health services: A contribution to workplace health. Retrieved December 14, 2017, from http://www.euro.who.int/_data/asset s/pdf_file/0007/115486/E77650.pdf.

Williams, D. P., Cash, C., Rankin, C., Bernardi, A., Koenig, J., \& Thayer, J. F. (2015). Resting heart rate variability predicts selfreported difficulties in emotion regulation: A focus on different facets of emotion regulation. Frontiers in Psychology. https://doi. org/10.1210/jc.2015-1748.

Wulsin, L. R., Horn, P. S., Perry, J. L., Massaro, J. M., \& D’Agostino, R. B. (2015). Autonomic imbalance as a predictor of metabolic risks, cardiovascular disease, diabetes, and mortality. The Journal of Clinical Endocrinology \& Metabolism, 100(6), 2443-2448.

Wulsin, L. R., Horn, P. S., Perry, J. L., Massaro, J. M., \& D’Agostino, R. B. (2016). The contribution of autonomic imbalance to the development of metabolic syndrome. Psychosomatic Medicine, 78(4), 474-480. https://doi.org/10.1097/PSY.0000000000000290.

Zahn, D., Adams, J., Krohn, J., Wnezel, M., Mann, C. G., Gomille, L. K., Jacobi-Scherbening, V., \& Kubiak, T. (2016). Heart rate variability and self-control-A meta-analysis. Biological Psychology, 115, 9-26. https://doi.org/10.1016/j.biopsycho.2015.12.007.

Publisher's Note Springer Nature remains neutral with regard to jurisdictional claims in published maps and institutional affiliations. 